\title{
Survival and hospitalization among patients with acute myeloid leukemia treated with azacitidine or decitabine in a large managed care population: a real-world, retrospective, claims-based, comparative analysis
}

\author{
B Douglas Smith ${ }^{1 \dagger}$, Charles L Beach², Dalia Mahmoud ${ }^{3 \dagger}$, Laura Weber ${ }^{3}$ and Henry J Henk ${ }^{4 *+}$
}

\begin{abstract}
Background: This study examined patient outcomes using real world data for acute myeloid leukemia (AML) patients initiating treatment.

Methods: A retrospective, administrative claims-based, comparative analysis was developed to study outcomes for AML patients initiating treatment with decitabine or azacitidine between January 2006 and June 2012.

Results: Treatment with azacitidine was associated with a longer median overall survival (10.1 versus 6.9 mos., $p=0.007$ ) and a lower risk of hospitalization (HR 0.787, $\mathrm{p}=0.02$ ) compared to treatment with decitabine.

Conclusions: This analysis of the outcomes of real-world treatment of AML patients with demethylating agents suggests that azacitidine may result in clinically superior outcomes than decitabine.
\end{abstract}

Keywords: Acute myeloid leukemia, Survival, Hospitalization, Azacitidine, Decitabine, Managed care, Real-world

\section{Background}

Acute myeloid leukemia (AML) is the most common form of leukemia in US adults, is associated with the largest number of deaths [1], and is particularly challenging for clinicians treating elderly patients who often have limited treatment options due to their age and co-morbid conditions. The National Comprehensive Cancer Network (NCCN) guidelines consider patients aged 60 years or older eligible for highintensity induction therapy in limited circumstances [1]. This is in part due to the finding that the percentage of patients who demonstrate clinical characteristics making them fit for high-intensity chemotherapy decreases with age [2]. In fact, the use of traditional, standard-dose induction chemotherapy for the treatment of AML has been shown to decrease with age $[3,4]$. In US cancer trials, it is common

\footnotetext{
*Correspondence: Henry.Henk@optum.com

${ }^{\dagger}$ Equal contributors

${ }^{4}$ Health Economic and Outcomes Research, Optum, Eden Prairie, MN, USA

Full list of author information is available at the end of the article
}

that older patients are excluded from participating based on their age at diagnosis [5].

The limitations noted are not without reason as intensive, chemotherapy-based induction carries a comparably higher risk of death in older patients compared with younger ones (overall survival [OS]; ranges from 3.5 months [ $>75$ years of age] to 18.8 months $[\geq 56$ to $\leq 75$ years of age]; overall mortality hazard ratio [HR] of 1.2-1.3) [6,7]. Yet, these concerns must be weighed carefully against the finding that even in those patients who elect intensivetreatment there is a limited overall survival benefit. With a median age at diagnosis of AML in the US of 66 years [6], the challenge faced by clinicians in the treatment of elderly patients with newly diagnosed AML is quite real.

Hypomethylating agents have been used as lowerintensity AML induction treatments, particularly in patients age $\geq 60$ years [1]. However, outcome data from clinical studies are inconsistent regarding the use of both azacitidine (Vidaza ${ }^{\circledR}$, Celgene Corporation, Summit, NJ) and decitabine (Dacogen ${ }^{\circ}$ Eisai Inc., Woodcliff Lake, NJ) 
in the treatment of the elderly population with AML. A prospective trial examining the use of azacitidine (AZA) to treat elderly patients with AML found an increased OS when compared to conventional or best care (median OS 24.5 mos., 15.0 mos., respectively; HR 0.58; 95\% CI $0.43-0 \cdot 77 ; \mathrm{p}=0.0001$ ) [8]. Additionally, a post-hoc analysis of a subset of elderly patients with AML (refractory anemia with excess blasts in transformation [RAEB-T] patients) found a longer overall survival for AZA-treated patients compared to conventional care (OS 24.5 mos., 16 mos. respectively; HR $0.47 ; 95 \% \mathrm{CI}, 0.28$ to $0.79 ; \mathrm{p}=0.005$ ) [9]. A recent retrospective, single-site study in elderly patients also found significant survival advantage in favor of azacitidine vs. best supportive care although no difference in the improvement of OS with azacitidine when compared with intensive chemotherapy despite the finding that azacitidine was associated with less hospitalization (median of 0.5 days versus 56 days, respectively in the first 3 months) and fewer RBC and platelet transfusions (median of $2.7 \mathrm{vs.}$ 7 per month respectively during the first 3 mos.) [10]. Likewise, the use of decitabine in elderly patients with AML showed a clinical benefit in OS (albeit non- significant) compared to supportive care alone (median OS 7.7 vs. 5.0 months respectively, $\mathrm{HR}$ 0.85, $\mathrm{p}=0.108$ ) [11]. In addition, two, open-label, single arm studies found a similar median OS rates with decitabine (DAC) therapy in elderly AML patients (median OS of 7.7 and 5.5 months) $[12,13]$. The inconsistent results are further difficult to interpret in that the AML populations examined were different (approximately $50-75 \%$ of AZA-treated patients had had $<30 \%$ blasts whereas only 3.1-28\% DAC-treated patients met this criterion) [8,9,11-13].

Retrospective comparisons of hypomethylating agents and chemotherapy in elderly patients often show higher response rates with chemotherapy-based regimens, but not an increase in survival [14]. These outcomes are conflicted with the finding that hypomethylating agents result in improved OS in controlled trials and raise the concern of loss of efficacy when using this class of agents outside of clinical trials. In fact, the potential importance of hypomethylating agents for the treatment of elderly patients with AML may be not fully realized. Understanding real-world results may better frame the treatment approaches for this group of patients. The purpose of this study is to examine the real world translation of the use of hypomethylating agents to treat elderly patients with AML by assessing patient outcomes for those initiating treatment with azacitidine or decitabine. The objectives were to describe overall survival for patients who initiated each treatment, assess the clinical impact of the treatment including describing the time to hospitalization after treatment initiation, and the occurrence of infections and bleeding events.

\section{Results}

\section{Demographic and clinical characteristics}

Of the 1,922 commercial or Medicare Advantage enrollees who initiated treatment for AML, a total of 487 patients (AZA, $n=288$, DEC, $n=199$ ) were determined eligible for analysis. Of the patients excluded, 513 met the criteria of not being continuously enrolled 6 months prior to index and 922 did not have a claim for AML diagnosis 6 months prior to or within 60 days of index date.

Demographic and clinical characteristics for each cohort are in Table 1 . The mean age of the cohorts (AZA $70.3 \pm 11.8$ years, DEC $69.4 \pm 11.6$ years) indicated the populations were elderly with over $70 \%$ of the each cohort being $\geq 65$ years of age. Most patient characteristics were similar between cohorts. There were two notable differences between the groups: the decitabine cohort had significantly more hospitalizations (62\% AZA, 71\% DEC; $\mathrm{p}=0.0323$ ) and a higher baseline mean Charlson comorbidity score (3.0 AZA, 3.4 DEC; p = 0.0140) noted during the pre-index period.

\section{Overall survival}

Overall survival was significantly better in the AZAtreated cohort compared with patients in the DECtreated cohort (10.1 months vs. 6.9 months respectively; $\mathrm{p}=0.007$, Figure 1) and treatment with azacitidine resulted in a significantly longer time to death when compared with decitabine treatment (adjusted HR 0.721, p = 0.008). Covariates (listed in Table 2) which were significantly associated

Table 1 Demographic and clinical characteristics

\begin{tabular}{|c|c|c|c|}
\hline & $\begin{array}{l}\text { Azacitidine } \\
(\mathrm{n}=288)\end{array}$ & $\begin{array}{l}\text { Decitabine } \\
(\mathrm{n}=199)\end{array}$ & p-value \\
\hline \multicolumn{4}{|c|}{ Demographic characteristics } \\
\hline Age, mean (SD) & 70.3 years $(11.8)$ & 69.4 years $(11.6)$ & 0.3890 \\
\hline $18-64$ years old & 25.3 & 28.6 & - \\
\hline $65+$ years old & 74.7 & 71.4 & - \\
\hline Gender (\% male) & 59.0 & 54.8 & 0.3510 \\
\hline Insurance Type & & & 0.2450 \\
\hline Commercial Insurance (\%) & 46.5 & 41.2 & - \\
\hline Medicare Advantage (\%) & 53.5 & 58.8 & - \\
\hline \multicolumn{4}{|c|}{ Clinical characteristics } \\
\hline MDS diagnosis *, \% & 54.5 & 51.9 & 0.549 \\
\hline RBC transfusion*, \% & 51.0 & 54.8 & 0.4185 \\
\hline ESA utilization** & 26.4 & 25.1 & 0.754 \\
\hline G/GM-CSF utilization** & 18.1 & 19.1 & 0.771 \\
\hline $\begin{array}{l}\text { Charlson Comorbidity } \\
\text { Index* mean (SD) }\end{array}$ & $3.0(1.7)$ & $3.4(1.8)$ & 0.0140 \\
\hline Hospitalization* & 61.5 & 70.9 & 0.0323 \\
\hline
\end{tabular}

*baseline period, 6 months pre-index.

**follow-up period, post-index. 


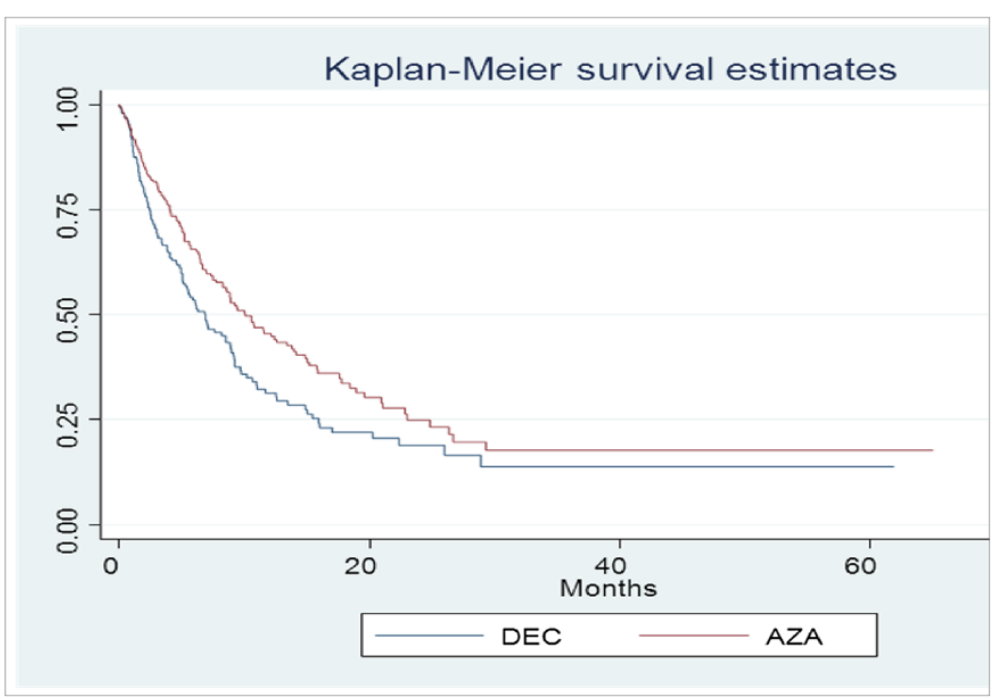

Figure 1 Overall survival.

with poorer survival were being male (adjusted HR 1.522, $\mathrm{p}=0.001)$ and those who had a prior red blood cell $(\mathrm{RBC})$ transfusion (adjusted HR 1.373, $\mathrm{p}=0.018$ ). Other covariates that were not independently associated with time to death include prior diagnosis of myelodysplastic syndrome (MDS) and type of insurance. After controlling for these variables, neither Charlson comorbidity score nor prior hospitalization were associated with time to death (Table 2).

Table 2 Time-to-event analyses: Cox PH models of mortality and hospitalization

\begin{tabular}{|c|c|c|c|c|}
\hline & \multicolumn{2}{|c|}{ Death } & \multicolumn{2}{|c|}{ Hospitalization } \\
\hline & $\begin{array}{c}\text { Adjusted } \\
\text { hazard ratio }\end{array}$ & $\overline{p \text {-value }}$ & $\begin{array}{c}\text { Adjusted } \\
\text { hazard ratio }\end{array}$ & $\overline{p \text {-value }}$ \\
\hline Azacitidine $^{a}$ & 0.721 & $(0.008)^{* *}$ & 0.787 & $(0.020)^{*}$ \\
\hline Age & 1.031 & $(0.000)^{* *}$ & 0.999 & $(0.818)$ \\
\hline Gender Male & 1.522 & $(0.001)^{* *}$ & 1.097 & $(0.372)$ \\
\hline $\begin{array}{l}\text { Prior Diagnosis } \\
\text { of } \text { MDS }^{\mathrm{b}}\end{array}$ & 0.878 & $(0.283)$ & 1.131 & $(0.225)$ \\
\hline $\begin{array}{l}\text { Charlson comorbidity } \\
\text { index score }{ }^{c}\end{array}$ & 0.937 & $(0.088)$ & 1.001 & $(0.974)$ \\
\hline Prior RBC transfusion ${ }^{d}$ & 1.373 & $(0.018)^{*}$ & 1.321 & $(0.012)^{*}$ \\
\hline $\begin{array}{l}\text { Medicare Advantage } \\
\text { enrollee }^{\mathrm{e}}\end{array}$ & 0.973 & $(0.855)$ & 0.993 & $(0.954)$ \\
\hline Prior Hospitalization ${ }^{f}$ & 1.303 & $(0.069)$ & 1.061 & $(0.618)$ \\
\hline Observations & 487 & & 487 & \\
\hline
\end{tabular}

p-values in parentheses.

*significant at $5 \%$; ** significant at $1 \%$.

Reference groups: ${ }^{a}$ decitabine, ${ }^{b}$ no diagnosis of MDS in the 6 months prior to starting treatment with a demethylating agent, ${ }^{~} \mathrm{C}$ Charlson comorbidity index is a continuous score from 0 to 24 (most comorbidity burden), ${ }^{\text {nno RBC }}$ transfusion in 6 months prior to starting treatment with a demethylating agent, ${ }^{\mathrm{e}}$ commerical insurance, ${ }^{\mathrm{f}}$ no hospitalizations in 6 months prior to starting treatment with a demethylating agent.

\section{Hospitalization}

Overall hospitalization rates were lower in the AZAtreated cohort compared with the DEC-treated cohort (2.90 vs. 3.42 per person-year, Figure 2). Likewise, patients in the AZA-treated cohort also had a significantly longer median time to first hospitalization when compared with DEC-treated patients (1.9 vs. 1.4 months respectively; $\mathrm{p}=0.015)$ and an overall lower risk of hospitalization (adjusted HR 0.787, $\mathrm{p}=0.02$ ) (Table 2). Prior RBC transfusions were found to significantly increase the time to hospitalization (adjusted HR 1.373, $\mathrm{p}=0.018$ ) while no other covariates examined were found to impact the risk of hospitalization. The primary reason for hospitalization in both cohorts were infections (AZA 46.6\%, DEC 47.1\%). Less common reasons for hospitalization are bleeding events $(5.1 \%$ AZA, 7.3\% DEC) and both a bleeding and infection event (7.6\% AZA, 9.9\% DEC). Just over one third of the hospitalizations in each cohort were not associated with either bleeding or infections.

\section{Discussion}

This real-world study was designed to provide data to supplement clinical trial data and to answer the important question of the effectiveness of treatment in actual clinical practice. These findings are consistent with clinical trials in which the OS for azacitidine $[9,15,16]$ has been found to be longer than the OS observed in trials of decitabine $[11,12]$. While, the median OS for AML patients treated with azacitidine in this study was shorter than what was reported in clinical trials $[9,15,16]$, it was still longer than OS for patients treated with decitabine either in this retrospective study or previous trials $[11,12]$. Our findings were also consistent with the data 


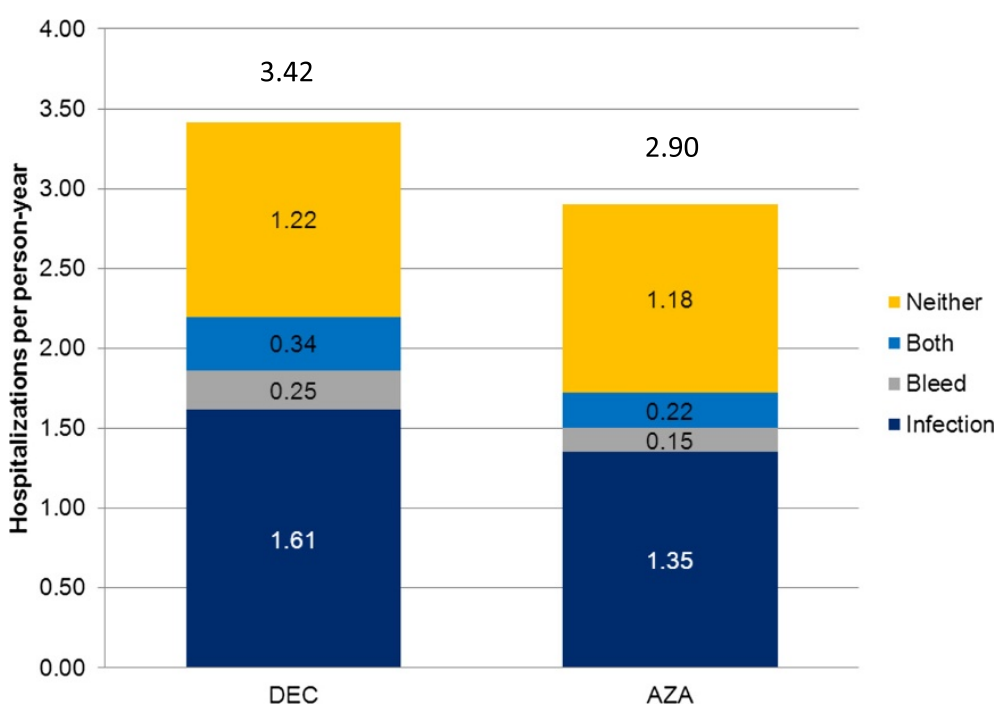

Figure 2 Reasons for hospitalization.

generated in another usual care setting, which showed a similar magnitude of overall survival as the present analysis. Maurillo et al. reported that the OS for azacitidine in a non-trial context was a median of 9 months among patients who were newly-treated for AML $(n=35$, median age 77) [17].

Real-world data regarding the effect of treatment on hospitalizations, bleeding and infections are very limited. Fenaux et al. found a similar hospitalization rate for azacitidine-treated patients (3.4 per patient year) [9]. Reported rates of infection ( 0.64 per patient-year) and bleeding (0.56 per patient year) rates for azacitidinetreated were lower than the rates found in this study [15]. These differences may be due to different methodological definitions of these events. Clearly, additional real-world evidence is needed to assess treatment associated hospitalization and comparative safety for therapeutic options available to treat AML.

Several limitations exist for retrospective claims analyses. Administrative claims data in general are limited by the potential for misclassification of diagnosis, study covariates, and/or outcomes. Most importantly, patients were not randomly assigned to treatment. Since common clinical measures of disease severity and patient prognosis (absolute neutrophil count [ANC] levels, platelet counts, and blast counts) are not available claims data, the two cohorts may be unbalanced with one cohort at higher risk for disease progression. This would be the case if physician select hypomethylating agents based on severity and prognosis. In our analyses we adjust for variables available in the claims data that are correlated with these measures (prior hospitalizations, MDS diagnoses, and red blood cell transfusions, use of erythropoietin-stimulating agents [ESA] and granulocyte colony-stimulating factors). Furthermore, we can find no published literature that suggests, or recommends, physicians select patients with a poor prognosis for treatment with either agent. Administration schedules for each therapy were not controlled and therefore dosing and/or administration variances may limit the results. While we recognize that dosing and adherence plays an important role in outcomes, this is a real-word study and the intent was to analyze how selection of treatment was related to outcomes. Death data likely underestimate total deaths, but we do not expect differential bias between cohorts.

\section{Conclusion}

The clinical results determined by well-designed and controlled clinical trials are often not able to be duplicated when applied as standard of care outside of the pre-specified treatment, monitoring and support plans outlined by the clinical protocol. It is important to recognize this when assessing these "real-world" outcomes that show an overall survival advantage for AML patients who were treated with azacitidine compared to decitabine. The survival time in azacitidine-treated patients was further differentiated from those treated with decitabine by being associated with less time in the hospital. These data held up well after testing for numerous factors that may otherwise independently affect results. Although there are no studies that compare outcomes between patients randomly assigned to azacitidine or decitabine, physicians who choose to treat their AML patients with azacitidine outside of the confined of a clinical trial should have confidence in their choice. 


\section{Methods}

\section{Study design}

This study was a retrospective, administrative claims-based analysis of patients diagnosed with acute myeloid leukemia who were treated with azacitidine or decitabine to assess real-world patient outcomes. Medical and pharmacy claims data used in the analysis were for services or products provided from January 1, 2006 through June 20, 2012.

\section{Data source}

Data for this retrospective claims data-based analysis of patients from a large US commercial health plan were obtained from the Optum Research Database. The database contains de-identified medical and pharmacy claims data for over 33 million commercially-insured members annually, as well as eligibility information and linked mortality data from Social Security Administration death master files. Approximately 3.6 million Medicare Part C enrollees (commonly referred to as Medicare Advantage) and 5 million Medicare Part D enrollees since 2006 are included in the database. The population contained within the Optum Research Database is geographically diverse across the US, with a concentration of patients in the South, and therefor fairly representative of the U.S. population.

No identifiable protected health information was extracted or accessed during the course of the study. Pursuant to the Health Insurance Portability and Accountability Act, the use of de-identified data does not require Institutional Review Board approval or waiver of authorization.

\section{Study population}

Subjects included were commercial or Medicare Advantage health plan members, $\geq 18$ years of age with a diagnosis of AML (ICD-9-CM claim of 205.0x) in baseline or within 6 months prior to or within 60 days post initiation of treatment with either azacitidine (CPT J9025) or decitabine (CPT J0894) between January 1, 2006 and April 30, 2012 (index date). Continuous enrollment was required from 6 months prior to the index date (baseline period) to the earlier of death, disenrollment from the plan, or June 30, 2012. The follow-up period was variable and continued from the index date to the earlier of death, disenrollment from health plan, or June 30, 2012. Patients were excluded if they were $<18$ years of age at index date or had a claim for azacitidine or decitabine in the baseline period. Two cohorts were created based on treatment (azacitidine-treated patients and decitabinetreated patients).

\section{Demographic and clinical characteristics}

Patient demographics examined at index for each treatment include age, gender, geographic region (Northeast, Midwest, South, West) and insurance type (commercial or Medicare Advantage). Clinical characteristics examined include treatment type (azacitidine or decitabine), history of MDS diagnosis and RBC transfusion in baseline period and baseline or post-index ESA and granulocyte or granulocyte-macrophage colony-stimulating factor use. Baseline calculations were performed to identify the Quan Charlson comorbidity score [18] and hospitalization.

\section{Patient outcomes}

The primary patient outcome was OS, calculated as the time period from the index date until the date of death. A second outcome examined was hospitalization. All outcomes were measured in the post-index period, inclusive of the index date. The overall number of hospitalizations was measured and calculated as 'hospitalizations per person-year'. Reasons for hospitalization were also captured based on the primary diagnosis code listed on the claim. These specific hospitalizations include infection, bleed, and cardiac related events. Finally, the time to first hospitalization after the index date was calculated for both all-cause and AML-related hospitalizations.

Use of a transfusion was determined based on evidence of a claim for at least one red blood transfusion during the follow-up period. Transfusion dependence was defined as those with evidence (a claim in any position on claim form) of at least two transfusion events on separate days during an eight-week period as indicated by procedure and/or revenue codes and service dates for whole or red blood cell transfusions. The service date for the first transfusion in the first episode of transfusion-dependence in the follow-up period is defined as the transfusion dependence.

\section{Statistical analysis}

Unadjusted comparisons of OS and time to first hospitalization between azacitidine and decitabine patients were made via Kaplan-Meier estimator to account for variable length of follow-up. A Cox proportional hazards model was used to examine the relationship between choice of demethylating agent and OS, time to 1st hospitalization, and transfusion dependence while controlling for age, gender, comorbidity score, prior MDS diagnosis, prior red blood cell transfusion, prior hospitalizations, and insurance type. All analyses were conducted using version 10.1 of the STATA/SE software package (Stata Corp, College Station, TX).

\section{Competing interests}

The study and manuscript preparation were funded by Celgene. B. Douglas Smith, MD declares that he has no competing interests. Charles L. Beach, PharmD, Dalia Mahmoud, MBA, and Laura Weber are employees of Celgene and hold equity. Henry J. Henk, PhD is an employee of Optum, which was contracted by Celgene to conduct the study. 


\section{Authors' contributions}

All authors participated in the design of the study. $\mathrm{HJH}$ designed and conducted the retrospective claims research and performed the statistical analysis. All authors participated in drafting the manuscript. All authors read and approved the final manuscript.

\section{Acknowledgements}

We would like to thank Jane Sullivan, Optum, who programmed the dataset on behalf of Celgene. Additionally, we would like to thank Elizabeth J. Davis, PhD, Optum and Mark J. Bernauer, BS Pharmacy, Optum, who provided medical writing assistance on behalf of Celgene.

\section{Author details}

${ }^{1}$ Sidney Kimmel Comprehensive Cancer Center at Johns Hopkins, Baltimore, MD, USA. ${ }^{2}$ Hematology/Oncology Clinical Research and Development, Celgene, Summit, NJ, USA. ${ }^{3}$ Global Pricing and Market Access, Celgene, Summit, NJ, USA. ${ }^{4}$ Health Economic and Outcomes Research, Optum, Eden Prairie, MN, USA.

Received: 10 February 2014 Accepted: 16 March 2014

Published: 25 March 2014

\section{References}

1. National Comprehensive Cancer Network (NCCN): NCCN guidelines version 2: acute myeloid leukemia. 2013. http://www.nccn.org/professionals/ physician_gls/f_guidelines.asp\#aml.

2. Appelbaum FR, Gundacker H, Head DR, Slovak ML, Willman CL, Godwin JE, Anderson JE, Petersdorf SH: Age and acute myeloid leukemia. Blood 2006 107:3481-5.

3. Juliusson G, Antunovic P, Derolf A, Lehmann S, Mollgard L, Stockelberg D, Anderson JE, Petersdorf SH: Age and acute myeloid leukemia: real world data on decision to treat and outcomes from the Swedish Acute Leukemia Registry. Blood 2009, 113:4179-87.

4. Behringer B, Pitako JA, Kunzmann R, Schmoor C, Behringer D, Mertelsmann R, Lubbert M: Prognosis of older patients with acute myeloid leukemia receiving either induction or noncurative treatment: a single-center retrospective study. Annals Hematol 2003, 82:381-9.

5. Hutchins LF, Unger JM, Crowley JJ, Coltman CA Jr, Albain KS: Underrepresentation of patients 65 years of age or older in cancertreatment trials. New Eng J Med 1999, 341:2061-7.

6. Surveillance Epidemiology and End Results (SEER): SEER stat fact sheets: acute myeloid leukemia. Bethesda, MD: National Cancer Institute (NCI); 2012

7. Deschler B, de Witte T, Mertelsmann R, Lubbert M: Treatment decision-making for older patients with high-risk myelodysplastic syndrome or acute myeloid leukemia: problems and approaches. Haematologica 2006, 91:1513-22.

8. Fenaux P, Mufti GJ, Hellstrom-Lindberg E, Santini V, Finelli C, Giagounidis A, Schoch R, Gattermann N, Sanz G, List A, Gore SD, Seymour JF, Bennett JM, Byrd J, Backstrom J, Zimmerman L, McKenzie D, Beach C, Silverman LR, International Vidaza High-Risk MDS Survival Study Group: Efficacy of azacitidine compared with that of conventional care regimens in the treatment of higher-risk myelodysplastic syndromes: a randomised, open-label, phase III study. Lancet Oncol 2009, 10:223-32.

9. Fenaux P, Mufti GJ, Hellstrom-Lindberg E, Santini V, Gattermann N, Germing U, Sanz G, List AF, Gore S, Seymour JF, Dombret H, Backstrom J, Zimmerman L, McKenzie D, Beach CL, Silverman LR: Azacitidine prolongs overall survival compared with conventional care regimens in elderly patients with low bone marrow blast count acute myeloid leukemia. J Clin Oncol 2010, 28:562-9.

10. van der Helm LH, Scheepers ER, Veeger NJ, Daenen SM, Mulder AB, van den Berg E, Vellenga $E$, Huls G: Azacitidine might be beneficial in a subgroup of older AML patients compared to intensive chemotherapy: a single centre retrospective study of 227 consecutive patients. $J$ Hemat Oncol 2013, 6:29.

11. Kantarjian HM, Thomas XG, Dmoszynska A, Wierzbowska A, Mazur G, Mayer J, Gau JP, Chou WC, Buckstein R, Cermak J, Kuo CY, Oriol A, Ravandi F, Faderl S, Delaunay J, Lysa'k D, Minden M, Arthur C: Multicenter, randomized, open-label, phase III trial of decitabine versus patient choice, with physician advice, of either supportive care or low-dose cytarabine for the treatment of older patients with newly diagnosed acute myeloid leukemia. J Clin Oncol 2012, 30:2670-7.
12. Cashen AF, Schiller GJ, O'Donnell MR, DiPersio JF: Multicenter, phase II study of decitabine for the first-line treatment of older patients with acute myeloid leukemia. J Clin Oncol 2010, 28:556-61.

13. Lubbert M, Ruter BH, Claus R, Schmoor C, Schmid M, Germing U, Kuendgen A, Rethwisch V, Ganser A, Platzbecker U, Galm O, Brugger W, Heil G, Hackanson B, Deschler B, Dohner K, Hagemeijer A, Wijermans PW, Döhner H: A multicenter phase II trial of decitabine as first-line treatment for older patients with acute myeloid leukemia judged unfit for induction chemotherapy. Haematologica 2012, 97:393-401.

14. Quintas-Cardama A, Ravandi F, Liu-Dumlao T, Brandt M, Faderl S, Pierce S, Borthakur G, Garcia-Manero G, Cortes J, Kantarjian H: Epigenetic therapy is associated with similar survival compared with intensive chemotherapy in older patients with newly diagnosed acute myeloid leukemia. Blood 2012, 120:4840-5.

15. Silverman LR, McKenzie DR, Peterson BL, Holland JF, Backstrom JT, Beach CL, Larson RA: Further analysis of trials with azacitidine in patients with myelodysplastic syndrome: studies 8421,8921, and 9221 by the Cancer and Leukemia Group B. J Clin Oncol 2006, 24:3895-903.

16. Passweg JR, Pabst T, Blum S, Bargetzi M, Li Q, Heim D, Stussi G, Gregor M, Leoncini L, Meyer-Monard S, Brauchli P, Chaladon Y: Azacytidine for acute myeloid leukemia in elderly or frail patients: a phase II trial (SAKK 30/07). Leukemia lymphoma 2014, 55:87-91.

17. Maurillo L, Venditti A, Spagnoli A, Gaidano G, Ferrero D, Oliva E, Lunghi M, D’Arco AM, Levis A, Pastore D, Di Renzo N, Santagostino A, Pavone V, Buccisano F, Musto P: Azacitidine for the treatment of patients with acute myeloid leukemia: report of 82 patients enrolled in an Italian Compassionate Program. Cancer 2012, 118:1014-22.

18. Quan H, Sundararajan V, Halfon P, Fong A, Burnand B, Luthi JC, Saunders LD, Beck CA, Feasby TE, Ghali WA: Coding algorithms for defining comorbidities in ICD-9-CM and ICD-10 administrative data. MedCare 2005, 43:1130-9.

doi:10.1186/2162-3619-3-10

Cite this article as: Smith et al:: Survival and hospitalization among patients with acute myeloid leukemia treated with azacitidine or decitabine in a large managed care population: a real-world, retrospective, claims-based, comparative analysis. Experimental Hematology \& Oncology 2014 3:10.

\section{Submit your next manuscript to BioMed Central and take full advantage of:}

- Convenient online submission

- Thorough peer review

- No space constraints or color figure charges

- Immediate publication on acceptance

- Inclusion in PubMed, CAS, Scopus and Google Scholar

- Research which is freely available for redistribution 